\title{
Hybrid Nerve Sheath Tumor
}

National Cancer Institute

\section{Source}

National Cancer Institute. Hybrid Nerve Sheath Tumor. NCI Thesaurus. Code C121686.

A benign nerve sheath tumor characterized by the combination of histologic features seen in schwannomas, neurofibromas, and perineuriomas. 